\title{
Estado e empresariado nacionais na condução da política externa brasileira para a África no governo Lula
}

[ National private sector and state in the conduction of the Brazilian foreign policy for Africa during the Lula years

\section{Gustavo Miranda Puerari ${ }^{\mathrm{I}}$}

RESUMO $\cdot O$ artigo analisa interações entre membros do empresariado e o governo brasileiro durante o governo Lula, de 2003 a 20Io, no âmbito das políticas públicas domésticas e externa nacionais que teriam fomentado as relações com países africanos com vistas a ganhos instrumentais. Defende-se que tanto atores privados quanto estatais, por convergências e/ou associações de interesses, teriam obtido vantagens ao trabalhar sincronicamente. Enquanto o setor privado lograria diminuir seus custos políticos e financeiros com investimentos no exterior, o governo brasileiro, paralelamente, poderia utilizar-se desses investimentos privados como meio de expandir sua influência internacional e lograr seus objetivos. Nesse contexto, foram analisados três casos de empresas brasileiras que realizaram investimentos na África no período indicado. PALAVRAS-CHAVE - Lobbying; empresariado; política externa brasileira; África; Lula. • ABSTRACT • The ar- ticle analyses interactions between members of the Brazilian private sector and the Brazilian state apparatus during Luiz Inácio Lula da Silva's two terms as president, from 2003 to 20Io, within the domestic and foreign public policies' framework, which would have fomented relations with African countries pursuing instrumental gains. The article supports the thesis that actors from both private and governmental sectors achieves advantages as they emprehend synchronic actions. While the private sector succeeds in minimizing its operational and political costs in its external investments, the Brazilian government, in parallel, uses such private investments as a means of expanding its international influence and achieve its objectives. In light of this, three cases of Brazilian companies that invested in Africa during the investigated period, are analyzed. • KEYWORDS - Lobbying; private sector; Brazilian foreign policy; Africa; Lula.

Recebido em Io de maio de 2016

Aprovado em I3 de julho de 2016

PUERARI, Gustavo Miranda. Estado e empresariado nacionais na condução da política externa brasileira para a África no governo Lula. Revista do Instituto de Estudos Brasileiros, Brasil, n. 64, p. 275-295, ago. 2016.

DOI: http://dx.doi.org/Io.II6o6/issn.23I6-90IX.voi64p275-295

I Pontifícia Universidade Católica do Rio de Janeiro (PUC-Rio, Rio de Janeiro, RJ, Brasil). 


\section{INTRODUÇÃo}

A teoria liberal para análise de política externa tem como premissa fundamental a interdependência entre Estados e atores sociais privados que compõem as sociedades doméstica e transnacional (esta formada por atores privados envolvidos em ações que impactam outro(s) país(es) além daquele de origem). Esses atores privados influenciariam o comportamento estatal no plano internacional, tendo papel importante na definição das preferências dos Estados, pois "todo o governo representa alguns indivíduos mais que outros”.

As preferências e os comportamentos dos Estados seriam influenciados tanto por grupos domésticos mais preponderantes quanto pelas condições de interdependência existentes entre os diferentes países que compõem o sistema internacional. $\mathrm{Na}$ concepção liberal de política doméstica, o Estado não é ator monolítico, mas sim instituição representativa constantemente sujeita a modificações advindas de barganhas entre coalizões de atores sociais domésticos e transnacionais. A representatividade não apenas seria atributo de instituições que formam o Estado, mas também incluiria outras características do processo político, formais e/ou informais, que privilegiam interesses sociais particulares. Logo, pressões sociais transmitidas por indivíduos, grupos, instituições representativas e por práticas constituiriam sorte de transmissor pelo qual o poder e as preferências de um ou mais grupos se traduziriam em políticas de Estado, alterando as preferências estatais.

A abordagem supracitada, portanto, aponta para a centralidade dos grupos das sociedades doméstica e transnacional na formulação da política externa, sendo corroborada por Risse-Kappen 3 . Esse autor defende que: as relações transnacionais permeiam a política mundial; atores e coalizões transnacionais conscientemente buscam influenciar políticas, especialmente a política externa do Estado; as estruturas domésticas podem determinar a existência de canais de entrada para

2 MORAVCSIK, Andrew. Taking preferences seriously: a liberal theory of international politics. International Organization, 5I, 4, Outono, I997 (tradução nossa).

3 RISSE-KAPPEN, Thomas. Bringing transnational relations back in: non-state actors, domestic structures, international institutions. Cambridge: Cambridge University, I995. 
atores transnacionais (ou sociedade transnacional) em seu sistema político e prover os requisitos para as coalizões campeãs/players (grupos de maior poder) em influenciar/mudar políticas.

As estruturas domésticas, em resumo, determinariam a possibilidade de canais de comunicação entre a política doméstica e a sociedade transnacional, permitindo que grupos de maior poder mudassem os rumos de políticas a seu favor. Ressalta-se que a influência de grupos domésticos sobre o Estado na condução de políticas não seria determinante, como defendido na abordagem de Moravcsik 4 , sendo complementada pela abordagem de Risse-Kappen ${ }^{5}$ e, dessa maneira, reservando-se espaço de concertação política dentro do próprio governo, que pode ser mais ou menos permeável às interferências desses grupos domésticos ou transnacionais.

Especificamente no caso brasileiro, as interações entre grandes empresas e Estado não é nova, remontando ao governo Vargas, durante o qual foram criadas as federações industriais estaduais, por exemplo. Durante o regime militar, houve forte favorecimento por parte dos governos em prol de parte do empresariado doméstico em seus projetos de internacionalização, como a internacionalização de grandes construtoras civis brasileiras para a África ${ }^{6}$.

Aplicando-se o arcabouço teórico apresentado ao contexto brasileiro de 2003 a 20Io, analisa-se a interação entre o Estado e os grupos domésticos pertencentes ao empresariado nacional que também são membros da sociedade transnacional, à condição de que detenham operações tanto no Brasil quanto na África. O Estado brasileiro é considerado ator ativo, participante das negociações com os grupos domésticos e portador de interesses próprios, assim como o empresariado e os Estados receptores dos investimentos diretos por parte das empresas analisadas.

Os atores empresariais analisados nos estudos de caso, por sua vez, buscam influenciar políticas em seu proveito, articulando-se pelas esferas de poder estatal por meio de: participação direta em fóruns de debate e decisão; lobbying; participação acionária; linhas de financiamento etc. Dessarte, por meio de sua influência e de seu peso político-econômico no plano doméstico, esses poderosos atores privados fazem valer seus próprios interesses, por vezes aliando-se ao governo.

\section{RELAÇÃo GOVERNO-EMPRESARIADO NO BRASIL}

O governo brasileiro porta consigo demandas de grupos domésticos ao projetar-se no cenário internacional por meio de sua política externa e desempenha função central como indutor da ação coletiva ${ }^{7}$, havendo influenciado historicamente o próprio

4 MORAVCSIK, Andrew, op. cit.

5 RISSE-KAPPEN, Thomas, op. cit.

6 CAMPOS, Pedro Henrique Pedreira. Empresários, ditaduras e política externa brasileira. Continentes, Seropédica, ano 3, n. 4, 20I4.

7 BOSCHI, Renato; DINIZ, Eli; SANTOS, Fabiano. Elites políticas e econômicas no Brasil contemporâneo: a desconstrução da ordem corporativa e o papel do legislativo no cenário pós-reforma. São Paulo: Fundação Konrad Adenauer, 2000. 
padrão de atuação do empresariado e a estrutura de representação de seus interesses, com acesso direto ao aparelho burocrático estatal, com momentos de maior e de menor interação, dependendo do governo em questão ${ }^{8}$. A partir da redemocratização, porém, a prática de lobbying empresarial no governo começou a ter papel central na defesa dos interesses de atores econômicos privados.

Há, também, outros meios pelos quais o governo e atores empresariais podem sobrepor seus interesses. Lazzarini` expõe a composição acionária de diversas empresas privadas nacionais e a participação de entidades estatais nas mesmas, o que fomentaria a concertação de interesses convergentes e de associações. Dessa maneira, forma-se complexa rede de interesses, que se entrelaça e impacta na formulação de políticas públicas domésticas (econômica, industrial e comercial - estas últimas com aspectos também internacionais) e da política externa brasileira (PEB).

O processo histórico de incorporação dos atores do empresariado à política nacional durante a República ocorreu de modo corporativista ${ }^{\mathrm{IO}}$, iniciado na Era Vargas, num contexto de Estado centralizador, em que se consagraram a subordinação dos grupos de interesse e o princípio da tutela do Estado, integrados numa estrutura hierarquizada que se estendeu até o fim do regime militar. Desde a redemocratização brasileira, no entanto, a relação empresariado-Estado sofreu mudanças.

A partir de I985, o setor produtivo começou a empreender atuação política mais ativa por meio de suas lideranças ou entidades de cúpula. Estreitaram-se vínculos empresariais com segmentos do Estado, havendo diversos empresários ocupado posições da hierarquia estatal, tenha sido em cargos eletivos ou por indicação política. E, destaca-se, no contexto de negociações da Área de Livre Comércio da Américas (Alca), na década de I990, foi criada a Coalizão Empresarial Brasileira (CEB) ${ }^{\text {II }}$, que se tornou relevante fórum representativo dos interesses empresariais, buscando influenciar o governo em direção à concretização de seus objetivos.

De fato, não somente se verifica o governo ser pressionado por interesses de

8 Para outros detalhes sobre a interação entre governo brasileiro e empresariado a partir do regime militar brasileiro (de I964 a I985), ver: CAMPOS, Pedro Henrique Pedreira. Estranhas catedrais: as empreiteiras brasileiras e a ditadura civil-militar,I964-I988. Niterói: UFF, 20I4.

9 LAZZARINI, Sérgio G. Capitalismo de laços: os donos do Brasil e suas conexões. Rio de Janeiro: Elsevier, $20 I I$.

Io BOSCHI, Renato; DINIZ, Eli; SANTOS, Fabiano, op. cit.

II No ano de I996, o empresariado nacional, galgando mais acesso aos fóruns de discussão e decisórios, mobilizou-se e criou a CEB com a finalidade de: liderar, formular e coordenar o processo e as estratégias de influência do setor empresarial brasileiro nos processos de negociação internacional; capacitar os representantes empresariais; apresentar ao governo posições e recomendações empresariais; representar o empresariado em fóruns empresariais. A CEB foi organizada para receber e coordenar demandas de distintos setores produtivos a fim de influenciar a dinâmica da integração internacional econômica do país. Inicialmente, preocupava-se com as negociações para a Alca, buscando obter mais informação e engajamento em suas conferências, até então limitadas ao nível governamental. Os Fóruns Econômicos das Américas institucionalizaram a participação do empresariado nas negociações da Alca, levando a maior articulação entre as esferas privada e governamental. Atualmente, consolidou-se como canal de interlocução com o governo em negociações internacionais. OLIVEIRA, Amâncio Jorge de; PFEIFER, Alberto. O empresariado e a política exterior do Brasil. In: LESSA, A. C.; OLIVEIRA, H. A. de (Org.). Relações internacionais do Brasil: temas e agendas. v. 2. São Paulo: Saraiva, 2006, p. 392. 
poderosas coalizões empresariais e promover os interesses destas, mas também grandes empresas sendo utilizadas instrumentalmente pelo Estado em seus objetivos político-econômicos, como numa escolha de coalizões campeãs/players. No governo Lula, os fóruns empresariais perderam relevância, tendo sido dado maior destaque às players $^{12}$. Notam-se, portanto, diversas maneiras de articulação público-privado: desde esforços de associações empresariais em diálogo com o setor público até participações acionárias e laços clientelistas. O governo pode, nesse âmbito, buscar influenciar diretamente escolhas privadas por meio de seus parâmetros de regulação e ações de proteção seletiva àquelas coalizões de atores produtivos mais influentes.

No período de 1990 a 2002, diversas empresas estatais foram privatizadas e optou-se pela venda de controle em bloco. Nesse processo, fundos de pensão de estatais e o Banco Nacional de Desenvolvimento Econômico e Social - BNDES, por meio da criação de consórcios com empresas privadas, tornaram-se donos de parte dessas firmas, evidenciando-se associação de interesses entre atores privados e o Estado por meio de participações acionárias, de financiamentos por parte de entidades governamentais e de concessões do governo (serviços, estradas, etc.) ao setor privado.

A participação acionária de atores privados nacionais, de capital privado ou público, em companhias previamente privatizadas ${ }^{13}$, ter-se-ia intensificado no governo Lula, como no caso da Vale, da qual um grande número de ações foi adquirido pelo BNDES e por fundos de pensão de estatais, que se mantiveram no grupo controlador. Assim, o governo brasileiro até mesmo aumentou seu poder decisório dentro da estrutura de algumas companhias privadas.

No governo Lula, verificou-se aumento considerável do número de empresas brasileiras que abriram seu capital na bolsa de valores. Tal movimento reforçou diversos elementos característicos da associação governo-empresariado, havendo muitas empresas conquistado apoio político-financeiro e, até mesmo, participação acionária por parte do governo, no que possibilitaria maior interferência governamental, um modo pelo qual o empresariado tornar-se-ia parceiro e/ou instrumento daquele para seus fins:

A irradiação da presença do governo na teia societária das empresas brasileiras suscita uma série de questionamentos. Embora as participações do BNDES e dos fundos de pensão de estatais sejam minoritárias, estes são atores que agem em uníssono e em associação com outros donos alinhados às iniciativas do governo. Dessa forma, possibilitam que o braço estatal interfira nas dinâmicas internas do setor privado [e vice-versa]. [...] Cultivando laços com o sistema político, e especialmente com a coalizão vigente, os grupos empresariais podem contrabalançar o poder de influência do governo e [...] ter acesso a oportunidades e recursos diferenciados ${ }^{\mathrm{I}}$.

I2 PUERARI, Gustavo M. Empresariado e política externa brasileira para a África: convergências e associações no governo Lula. Dissertação (Mestrado). Instituto de Relações Internacionais - IRI da Pontifícia Universidade Católica do Rio de Janeiro - PUC-Rio, Rio de Janeiro, 2012.

I3 LAZZARINI, Sérgio G., op. cit.

I4 Ibidem, p. II2-II3. 


\section{POLÍtICAS PÚbliCAS E INTERNACIONALIZAÇÃo DE EMPRESAS}

Por intermédio de suas políticas externa, das políticas comercial e industrial (estas duas nos planos doméstico e internacional) e econômica (no âmbito nacional), o Estado tanto representa interesses de grupos domésticos quanto procura concretizar seus próprios. Tais políticas públicas ${ }^{15}$ são conjuntos articulados e estruturados de ações e incentivos que buscam alterar uma realidade em resposta a demandas e interesses dos atores envolvidos. É necessária uma relação cada vez mais sinérgica entre a política externa e as outras políticas públicas domésticas a fim de aperfeiçoar o padrão de inserção internacional do Brasil ${ }^{16}$.

No governo Lula, o desenvolvimento industrial ganhou proeminência, tendo sido criadas e implementadas duas políticas de abrangência nacional. A Política Industrial, Tecnológica e de Comércio Exterior de 2008 foi mais abrangente que sua correlata de 2003 e incluiu sete programas de financiamento do BNDES destinados a setores produtivos nacionais de destaque (aeronáutica; petróleo, gás natural e petroquímica; bioetanol; mineração; aço; papel e celulose; carnes) ${ }^{17}$.

Nesse contexto de associações e convergências entre os setores público e privado e promoção de políticas públicas uníssonas a fim de lograr o atendimento de interesses de membros do empresariado e do governo em questão, deve-se entender a ligação governo-empresariado e também a motivação por parte do setor privado em internacionalizar-se.

Há custos de internacionalização que envolvem gastos com o próprio estabelecimento da companhia no exterior, custos de adquirir informação sobre o novo país, flutuação cambial, possível discriminação contra empresas estrangeiras praticadas por governos, etc. É nesse âmbito de riscos que as políticas públicas do governo podem auxiliar o processo de internacionalização da firma. E, no caso do Brasil, verifica-se que, historicamente, o Estado vem apoiando certos grupos empresariais privados nesse âmbito ${ }^{\mathrm{I}}$.

As políticas públicas citadas são planos do governo para alocar recursos com o fim de atingir objetivos econômicos e políticos nacionais de longo prazo, como crescimento e competitividade internacional. Tais políticas podem afetar certas empresas mais que outras ao fazer com que essas firmas desviem-se de seus critérios

I5 De acordo com Pinheiro e Milani, a política externa é uma política pública e tem desenvolvido relação cada vez mais estreita com as demais. Englobando outros atores e passando a defender interesses setoriais, a agenda externa nacional tornou-se mais complexa a partir da década de I990 com o aprofundamento dos impactos da globalização no país e das reformas neoliberais. PINHEIRO, Leticia; MILANI, Carlos R. S. (Org.). Política externa brasileira: as práticas da política e a política das práticas. Rio de Janeiro: FGV, 20I2, p. 334-335.

I6 ARDISSONE, Carlos Maurício Pires e Albuquerque. Ideias, instituições e lideranças na política externa brasileira de propriedade intelectual: uma abordagem comparada dos governos Fernando Henrique Cardoso e Luiz Inácio Lula da Silva (I995-20IO). Tese (Doutorado). Instituto de Relações Internacionais - IRI, Pontifícia Universidade Católica do Rio de Janeiro - PUC-Rio, Rio de Janeiro, 20 II.

I7 PERES, Wilson; PRIMI, Annalisa. Theory and practice of industrial policy: evidence from the Latin American experience. CEPAL, Serie Desarrollo Productivo, Santiago do Chile, I87, n. I, p. I-5I, FEB. 2008.

I8 CAMPOS, Pedro Henrique Pedreira. Empresários, ditaduras e..., op. cit. 
estratégicos preestabelecidos em função de diretrizes ou incentivos governamentais, que podem diminuir custos políticos e financeiros. Em paralelo, poderosos grupos empresariais também pressionam o Estado para dividir tais custos e obter apoio em suas empreitadas internacionais.

No âmbito internacional, em que se verifica competitividade acirrada por conta do fenômeno da globalização, fazem-se necessárias tanto uma diplomacia comercial ativa que integre o governo e o setor privado quanto a aplicação de políticas públicas compatíveis com os fins almejados pelo Estado e pela parcela do empresariado que visa a atingir. Sendo assim, "a busca de crescimento sustentável e de redução de vulnerabilidade do governo brasileiro diante dos investimentos externos depende de ações conjuntas, o que inclui incentivar a internacionalização de empresas brasileiras (além das tradicionais políticas de promoção de exportação) ${ }^{\mathrm{I}}$.

A importância da internacionalização de empresas para o aumento do prestígio internacional dos países e para a redução da vulnerabilidade externa das próprias firmas justificaria a atuação proativa do setor público no apoio a investimentos no exterior. No caso do Brasil, seu objetivo, nesse âmbito,

[...] consiste em formar empresas fortes para competir em escala global, com apoio logístico do Estado e financeiro de instituições nacionais, como o BNDES. Sendo o Brasil um país de internacionalização econômica incipiente, sua política exterior tem longo caminho a percorrer antes de atingir a densidade dos países avançados, cujas multinacionais cooptam o respectivo governo, o qual entra em coalizões que exercem pressão sobre decisões [...] e alcançam, ao termo, regras internas e intergovernamentais a seu favor ${ }^{20}$.

Defende-se que o governo federal, durante o governo de Lula, assumiu que a internacionalização de empresas brasileiras permitiria ao país ocupar espaços de maior destaque no cenário mundial, como elemento de projeção internacional e de formação da imagem nacional, constituindo um instrumento da própria política externa. $\mathrm{O}$ empresariado, por sua vez, ao buscar oportunidades de negócio além-fronteiras não o faz somente motivado por apoio governamental, mas, principalmente, para obter maiores lucros, diversificar suas operações e minimizar seus riscos de entrada em novos contextos. Com o apoio do governo, os riscos e custos podem ser diminuídos sensivelmente e as novas operações no exterior, facilitadas.

Apesar de haver companhias brasileiras já em avançado nível de internacionalização, a maior parte segue ainda tímida nesse âmbito. O processo de internacionalização de empresas brasileiras ocorre, a priori, de maneira autônoma por parte das empresas, mas percebem-se interesse e apoio do governo federal a

I9 GUEDES, Ana Lúcia. Internacionalização de empresas como política de desenvolvimento: uma abordagem de diplomacia triangular. RAP, Rio de Janeiro, 40(3), mai.jun. 2006, p. 335-356. p. 347.

20 CERVO, Amado Luiz; BUENO, Clodoaldo. História da política exterior do Brasil. 3. ed. ampl. Brasília: UnB, 2008, p. 509. 
diversas iniciativas (por exemplo, por meio da abertura de linhas de crédito do BNDES) e de apoio logístico e de inteligência de parte do Ministério das Relações Exteriores - MRE (por exemplo, o estabelecimento de embaixada na Guinée ${ }^{2 \mathrm{I}}$ após decisão da Vale de realizar vultosos negócios de exploração de minas de ferro).

Somente no período de 2003 a 2006, primeiro mandato de Lula, foram realizadas 250 missões comerciais para 60 países, alcançando uma média de aproximadamente cinco viagens por mês. Desses países, nove eram africanos, a saber: África do Sul, Angola, Argélia, Camarões, Egito, Líbia, Moçambique, Namíbia e Nigéria ${ }^{22}$. Nesse esforço de fomentar a internacionalização de empresas nacionais com políticas e iniciativas públicas, por exemplo, o governo brasileiro, por meio da Receita Federal e dos Correios, ampliou o limite de exportações por remessa postal, criou programas de financiamento específicos pelo BNDES e abriu novas representações diplomáticas ${ }^{23}$.

São perceptíveis, portanto, indícios de convergências e de associações de interesses entre o governo e determinados atores do empresariado ${ }^{24}$. Nota-se uma estratégia deliberada do próprio Estado em desenvolver certos setores, muitas vezes até mesmo escolhendo players, incluindo a promoção internacional destes como forma de obter ganhos políticos em seus pleitos externos.

\section{A política eXterna brasileira para a África no governo lula}

Os anos Lula configuraram de maneira mais clara e direta as metas de inserção internacional do Brasil. Foi um período em que as políticas públicas foram combinadas de maneira a convergir e promover as mudanças propostas pelo governo, mobilizando parte do setor privado nacional na empreitada.

Repetidas vezes o ex-presidente Lula exortou o empresariado a unir-se ao governo

2I A companhia Vale se instalou oficialmente na Guiné em dezembro de 2005. A embaixada brasileira na capital do país, Conacri, foi estabelecida poucos meses depois, conforme os decretos presidenciais n. 5.770 de 8 de maio de 2006 e n. 6.422 de 2 de abril de 2008.

22 PASSOS, Ieda; GALVÃO, Fábio (Org.). Relatório de prestação de contas do Ministério do Desenvolvimento, Indústria e Comércio Exterior 2003-2006: Indústria e comércio exterior: caminhos para o desenvolvimento. [Brasília]: [s.n.] [2007?].

23 Durante o governo Lula, foram estabelecidas no mundo 4I novas embaixadas, sendo I7 em países africanos, a saber: Benin, Botsuana, Burkina Faso, Camarões, Congo, Etiópia, Guiné (cumulativa com a embaixada do Brasil de Serra Leoa), Guiné Equatorial, Mali, Mauritânia, Nigéria, República Democrática do Congo, São Tomé e Príncipe, Sudão, Tanzânia, Togo e Zâmbia.

24 É relevante expor que a Política (industrial) de Desenvolvimento Produtivo, de 2008, tinha metas expressamente relativas à África, ilustrando claramente a importância adquirida pelo continente para o governo brasileiro e os incentivos dados ao empresariado, tais como: ampliar o número de países e a qualidade da pauta exportadora para a África; aumentar o investimento brasileiro na África; conceder apoio financeiro a três projetos de investimento direto estrangeiro do Brasil na África até 2oIo. Ver: MINISTÉRIO DO DESENVOLVIMENTO, INDÚSTRIA E COMÉRCIO EXTERIOR. Programa Integração com a África. [s.l.], jun. 20Io. Disponível em: 〈http://www.pdp.gov.br/Relatorios\%2ode\%20Programas/AfricaI_com.pdf $\rangle$. Acesso em: 5 jun. 2012. 
na busca da diversificação comercial e a aproveitar mercados consumidores ainda pouco explorados e ansiosos por receber investimentos, demonstrando o empenho de seu governo em angariar apoio em outras partes do mundo aos pleitos do Estado brasileiro, mas também em utilizar a política externa como ponta de lança para o desenvolvimento do empresariado doméstico e a promoção de seu crescimento internacional. Nesse sentido, é importante ressaltar que, enquanto no governo Cardoso os investimentos brasileiros no exterior eram baixos, a partir do ano de 2004 começaram a crescer de forma acelerada: de US\$ Io bilhões naquele ano para US\$ 20 bilhões em $2008^{25}$, demonstrando a inclinação do empresariado doméstico a investir no exterior no contexto de incentivo promovido pelo governo analisado.

Das 38 maiores empresas brasileiras internacionalizadas elencadas pela Fundação Dom Cabral - FDC, I2 tinham subsidiárias na África (dentre as quais, as três alvo de estudo neste artigo). Segundo a entidade, as firmas transnacionais aproveitaram-se do momento propício para sua internacionalização na África por meio dos incentivos do governo e oportunidades crescentes ${ }^{26}$. Ou seja, do ponto de vista empresarial, investir no continente africano foi considerado mais seguro pelo apoio governamental e de suas políticas públicas, demonstrando a convergência e/ou associação de interesses de ao menos parte do empresariado e do governo na política externa de Lula, tendo em vista também as associações público-privadas analisadas em seção anterior.

O país demonstrou claramente seu interesse em assumir papel de maior destaque na governança global, ambição esta amplamente associada ao desejo de fomentar um arranjo mundial mais multipolar ${ }^{27}$. Nesse contexto, a agenda externa brasileira de 2003 a 2010 deu maior enfoque à integração com parceiros do Sul, tendo o país forjado novas alianças e aprofundado antigas, de que são exemplo: Fórum Ibas (Índia, Brasil e África do Sul); aproximação com Liga Árabe e União Africana; promoção das Cúpulas América do Sul-Países Ârabes; criação do G2o etc.

O aumento das relações bilaterais e multilaterais Sul-Sul pelo Brasil buscava promover a diminuição de assimetrias em instituições internacionais, procurando, em paralelo, aumentar a influência e o poder decisório do país no cenário internacional.

Vale ressaltar que os laços da política externa brasileira (PEB) com a África não são novos, tendo-se destacado, na primeira metade dos anos I960, com a Política Externa Independente, por meio da qual o Brasil começou a desempenhar uma ambiciosa aproximação com objetivos político-comerciais ${ }^{28}$. Na década de I970, no governo Geisel, restabeleceu-se na PEB o foco na África: os Estados recém-fundados ou em vias de se independer foram vistos como potenciais parceiros políticos na contestação

25 FDC - Fundação Dom Cabral. Ranking das transnacionais brasileiras 20Io: repensando as estratégias globais. Fundação Dom Cabral, Belo Horizonte. Disponível em: <http://www.fdc.org.br/professoresepesquisa/ publicacoes/Paginas/publicacao-detalhe.aspx?publicacao=I8I23 $\rangle$. Acesso em: Io maio $20 \mathrm{I2}$.

26 Ibidem.

27 ABDENUR, Adriana Erthal; SOUZA NETO, Daniel Marcondes de. Brazil and African security. CMI Reports, Bergen (Noruega), R, n. 4, 20I4, p. 50.

28 CERVO, Amado Luiz; BUENO, Clodoaldo. História da política exterior do Brasil. 3. ed. ampl. Brasília: UnB, 2008. 
das assimetrias Norte-Sul empreendida pelo Brasil em fóruns multilaterais. Nesse âmbito, o país passou a apoiar a independência negociada dos povos daquele continente, pressionando as metrópoles pelo mesmo reconhecimento. A aproximação Brasil-África transformou o país em parceiro político importante do continente, bem como comercial, tendo-se tornado nova fonte de suprimento de bens e serviços para os Estados africanos ${ }^{29}$.

Os governos dos anos I980 e I990 não foram marcados por incremento substantivo nas relações afro-brasileiras. Decerto o comércio continuou crescendo paulatinamente e coalizões multilaterais foram realizadas, como nas rodadas de negociações do Acordo Geral de Tarifas e Comércio - GATT/Organização Mundial do Comércio (OMC). Foi no governo Lula, porém, que houve a retomada do foco no continente africano, inovando-se claramente ao incorporar a projetos concretos de cooperação e de investimentos entre o Brasil e a África o desenvolvimento aliado ao combate à fome, discurso com forte apelo no continente ${ }^{3 \mathrm{I}}$, além de se intensificarem as trocas comerciais ${ }^{32}$. Para ilustrar o crescimento da importância das parcerias Sul-Sul no período estudado, de 2005 a 2009 o volume destinado pelo Estado brasileiro especificamente à cooperação para o desenvolvimento passou de R\$ 384,2 milhões para cerca de R\$ 724 milhões ao ano33.

O ex-presidente fez sua primeira visita a Estados africanos já em seu primeiro ano de mandato, em 2003, levando comitiva a Angola, África do Sul, Moçambique, Namíbia e São Tomé e Príncipe. No ano seguinte, foi promovido, no Cairo, o Seminário Empresarial Brasil-Egito, com vistas ao aumento do comércio bilateral.

Em 2006, foi realizada a Cúpula América do Sul-África, ressaltando os esforços do governo na aproximação entre as duas regiões e tratando de diversas áreas, tais como cooperação multilateral; comércio e investimento; e desenvolvimento de infraestrutura34. A formação dessa Cúpula remonta a dois fatos: à realização, em 2003, em Fortaleza, do Fórum Brasil-África (que objetivava reunir informações para avaliar e atualizar a PEB para a África) e à visita de Estado do presidente Lula à Nigéria,

29 Até os dias atuais, o Brasil é o único país na América do Sul ou Latina em que muitos países africanos têm representação diplomática. ABDENUR, Adriana Erthal; SOUZA NETO, Daniel Marcondes de, op. cit., p. 54 .

30 GATT: sigla, em inglês, de General Agreement on Tariffs and Trade.

3I Felipe Dutra de Carvalho Heimburger. Entrevista concedida por e-mail em 6 de junho de $20 I 2$.

32 Para detalhes sobre o aumento das trocas comerciais entre Brasil e África, ver: PUERARI, Gustavo M., op. cit.

33 IPEA - Instituto de Pesquisa Econômica Aplicada. Cooperação brasileira para o desenvolvimento internacional: 2005-2009. Brasília: Ipea, Agência Brasileira de Cooperação - ABC, 2010.

34 MINISTÉRIO DAS RELAÇÕES EXTERIORES. Abertura da I Reunião de Altos Funcionários do Mecanismo América do Sul-África. Brasília, Io de junho de 2008. Disponível em: <http://www.itamaraty.gov.br/ sala-de-imprensa/notas-a-imprensa/2008/o6/og/abertura-da-i-reuniao-de-altos-funcionarios-do >. Acesso em: I8 maio 20I2; MINISTÉRIO DAS RELAÇÕES EXTERIORES. Cúpula América do Sul-África - ASA. Abuja, 30 nov. 2006. Disponível em: <http://www.itamaraty.gov.br/temas/mecanismos-inter-regionais/cupula-america-do-sul20I3-africa-asa/>. Acesso em: 20 jul. 20II. Idem, Fórum Brasil-África. Fortaleza, 20 mai. 2003b. Disponível em: <http://www.itamaraty.gov.br/sala-de-imprensa/notas-a-imprensa/2003/05/20/forum-brasil-africa/> Acesso em: I9 mai. 2012. 
em abril de 2005, em que foi manifestado pelo homólogo nigeriano o interesse de aproximação dos países africanos com o Brasil.

De fato, de acordo com o MRE, durante seus mandatos, foram realizadas por Lula 33 viagens ao continente africano, a 23 países (em muitos casos, tratou-se da primeira visita de um chefe de Estado brasileiro ao local). No sentido oposto, o Brasil recebeu 47 chefes de Estado e de governo provenientes de 27 nações africanas ${ }^{35}$.

A I Cúpula América do Sul-Países Árabes foi realizada em Brasília no ano de 2005, tendo-se transformado em fórum permanente. Na ocasião, foram recebidos representantes de todos os países sul-americanos e de 22 nações árabes (das quais nove são africanas) ${ }^{36}$.

Em 2007, a República do Congo recebeu o mandatário brasileiro, onde, entre outros acordos, foi declarado apoio oficial ao pleito brasileiro de um assento permanente no Conselho de Segurança da Organização das Nações Unidas, mantido o apoio mútuo na defesa de interesses no âmbito da OMC e reiteradas as decisões de se criarem representações diplomáticas permanentes em suas capitais, aumentar o comércio bilateral e fomentar a instalação de empresas brasileiras no Congo. Como será visto no estudo de caso a respeito, empresas nacionais - destacadamente a Andrade Gutierrez - beneficiaram-se e apoiaram essa aproximação entre os Estados.

Finalmente, no ano de 20Io, último do segundo mandato de Lula, foi realizada a Cúpula Brasil-Comunidade Econômica dos Estados da África Ocidental (da qual a Guiné é membro), exortando a cooperação Sul-Sul em âmbito tanto político quanto econômico.

Contemplada como um todo, a África, com relação a 20Io, foi o quarto maior parceiro comercial do Brasil. Naquele ano, do total importado pelo país do continente africano (US\$ II,3 bilhões ou 5\% do total importado pelo Brasil naquele ano), 99\% eram bens primários e intermediários (destacadamente combustíveis). Por sua vez, das exportações brasileiras ao continente, $47 \%$ foram bens manufaturados, $2 \mathrm{I} \%$ semimanufaturados e $32 \%$ bens básicos ${ }^{37}$.

Vê-se que o Brasil empregou esforços em matéria de concertação políticodiplomática com os parceiros africanos, estimulando tanto o comércio bilateral quanto investimentos diretos, diminuindo os custos para as empresas nacionais que respondiam positivamente aos estímulos, com vistas a ganhos instrumentais tanto pelo setor privado quanto pelo Estado. O crescimento do comércio entre o Brasil e a África reflete relativa convergência das políticas públicas citadas e a adesão de atores do empresariado nacional a tais estímulos. Isso possibilitou ganhos políticos, além de oportunidades valiosas para membros do setor privado brasileiro, interessados em diminuir seus custos de entrada em novos mercados ou de obter apoio governamental em países onde já faziam ou haviam feito negócios anteriormente ${ }^{38}$.

35 Idem, Balanço de política externa: 2003 - 20Io. [Brasília]: MRE, [20II].

36 Idem, 2006.

37 Idem, 20 II.

38 Ver: CAMPOS, Pedro Henrique Pedreira. Empresários, ditaduras e..., op. cit. 


\section{ESTUDOS DE CASO}

Onde há assimetrias na distribuição de poder, há maior probabilidade de grupos demonstrarem comportamento oportunista e dividirem seus custos com os demais atores ${ }^{39}$. Tendo como base as relações Estado-empresariado no Brasil, podemos verificar que certos grupos privados mantêm relações próximas com o Estado, ocorrendo pressão de ambas as partes para a concretização de objetivos.

Entre 2003 e 20Io, como visto, o Brasil empreendeu uma política externa marcadamente Sul-Sul, posicionando a África como um de seus focos, envolvendo projetos de cooperação governamental e investimentos diretos de empresas brasileiras. A expansão destas teve um papel importante nas relações com a África, vista como instrumento de fortalecimento de laços com os países do continente.

A partir do arcabouço apresentado, foram realizados os três estudos de caso, apresentados a seguir.

\section{Vale na República da Guiné}

A empresa foi fundada pelo governo de Getúlio Vargas, em I942, sendo hoje denominada Vale e tendo capital aberto. Desde antes de sua privatização, em I997, a companhia mantém-se entre as maiores do país (e a maior do ramo de mineração) e, a partir daquele ano, acelerou seu processo de internacionalização. Atualmente, a empresa atua em diversos países, sendo $25 \%$ deles africanos.

Em 20I2, a composição acionária da Vale com relação ao seu capital total demonstrava a seguinte situação: o consórcio controlador Valepar detinha 34,I\% do total das ações preferenciais e ordinárias da companhia; o governo federal, por intermédio do BNDESPAR (braço do Banco Nacional de Desenvolvimento Econômico e Social - BNDES), possuía 5,6\% do total das ações da empresa Vale (além de I2 ações do tipo golden share $\left.{ }^{40}\right)$. O restante $(60,3 \%)$ estava pulverizado nas mãos de aplicadores nacionais e estrangeiros. Daqueles 34,I\% de ações sob a custódia da Valepar, o Bradesco detinha 2I\%; a Littel (que reúne fundos de pensão de algumas empresas estatais) e o BNDESPAR possuem 61\%; e a japonesa Mitsui, I8\% ${ }^{41}$.

Verifica-se, portanto, que o governo federal detém diretamente e por meio do BNDESPAR boa parte do controle acionário da companhia: além de fazer parte de seu grupo controlador da empresa, o BNDESPAR detém sozinho outros 5,6\% das ações da Vale. Ademais, fundos de pensão (Funcef, Petros, Funcesp, PREVI) de empresas sob controle governamental contam com participação expressiva e têm direito a voto. Ou seja, para qualquer decisão importante sobre investimentos ou medidas a serem tomadas pela empresa, deve-se passar pelo crivo do governo brasileiro.

\section{MORAVCSIK, Andrew, op. cit.}

40 As I2 ações golden share, por sua vez, permitem um controle ainda maior por parte do Estado brasileiro único detentor destas - sobre decisões da empresa.

4 I ROMERO, Cristiano. Sucessão na Vale terá solução interna. Valor econômico, Rio de Janeiro, 24 de março de 20II. Disponível em: <http://www.valor.com.br/arquivo/878877/sucessao-na-vale-tera-solucao-interna\#ixzzIvpNI6hL5> Acesso em: 24 maio 2012. 
A situação acima descrita pode funcionar dicotomicamente: tanto a empresa pode vir a utilizar-se de seus contatos, influência de seus controladores e peso econômico para pressionar o governo a acatar suas demandas, quanto o governo pode utilizar-se de seu controle acionário e de suas golden shares para fins próprios. Entretanto, tendo em vista que o grupo controlador é formado por outras empresas, o governo precisa também negociar com tais entes, visto que o capital social, lucros e prejuízos são compartilhados. Verifica-se, portanto, constante jogo de negociações entre grupos privados e o governo brasileiro em decisões importantes tomadas no âmbito dessa empresa, demonstrando, tal como preconizado por Moravcsik ${ }^{42}$, interdependência entre Estado e atores privados.

Outro modo pelo qual a empresa pode beneficiar-se de seus laços com o governo é com relação à obtenção de financiamentos públicos. Por meio do BNDES, o governo brasileiro faz empréstimos a companhias e, dentre o portfólio de financiamentos do banco, a Vale obteve vultosos empréstimos durante o governo Lula, como um de R\$ 774,6 milhões e outro de R 2,6 bilhões, em 2007, e um terceiro de R \$ 7,3 bilhões, no ano de $2008^{43}$.

Durante o governo Lula, houve aumento expressivo dos preços internacionais das commodities e a empresa aprofundou sua internacionalização, começando a operar em novos países, como a Guiné, objetivando extrair minério de ferro (então com preços recordes). A produção seria iniciada no ano de 2012.

A Vale optou por formar mão de obra local com um projeto de capacitação de técnicos para trabalharem nas operações vindouras, necessário tanto para seus negócios quanto para o desenvolvimento da Guiné, algo priorizado pelo presidente Lula com relação à atuação das empresas brasileiras no continente.

Apesar de Lula não haver visitado a Guiné durante seu mandato, fê-lo a convite da própria Vale em 20II, logo após deixar o cargo de presidente, participando de eventos com dirigentes da empresa e o presidente da Guiné. Isso não apenas reflete interesses da empresa em estabelecer-se no país ao usar a imagem de um influente político brasileiro com a boa reputação alcançada no continente africano, mas também os do Estado brasileiro, representado extraoficialmente por tal político que tinha deixado o posto de presidente havia pouco.

Como resultado do estreitamento das relações político-econômicas, foi estabelecida, em 2005, a embaixada da Guiné em Brasília, sendo pouco depois a vez da embaixada brasileira em Conacri. Confirmou-se, assim, o aumento do nível das relações bilaterais, principalmente à luz dos vultosos investimentos da Vale no país africano, ressaltando o controle acionário do próprio governo na companhia.

Tendo sido a decisão de investimento na Guiné acatada pelos acionistas controladores da Vale - dentre os quais o governo federal brasileiro, o BNDES (empresa pública) e outros fundos de pensão de empresas estatais -, pode-se concluir que o governo teve papel destacado na aceitação do investimento de exploração

42 MORAVCSIK, Andrew, op. cit.

43 BNDES. BNDES aprova financiamento de R\$ 7,3 bilhões para Vale realizar investimentos no Brasil até 20I2. BNDES, Rio de Janeiro, I/4/2008. Disponível em: <http://www.bndes.gov.br/SiteBNDES/bndes/bndes_pt/ Institucional/Sala_de_Imprensa/Noticias/2008/2008040I_not054_08.html> Acesso em: 20 maio 2012. 
mineral na Guiné. Ademais, proveu apoio político, marcado pelo estabelecimento da embaixada em Conacri e, em 20II, pela visita de Lula e pela vinda a Brasília do presidente guineense.

Logo, baseando-se em Moravcsik e Risse-Kappen ${ }^{44}$, os canais de comunicação entre a política doméstica e o membro privado da sociedade transnacional - a Vale permitiram que a empresa fosse tanto alvo de políticas públicas quanto as utilizasse a seu favor. Dessarte, os investimentos da Vale na Guiné seriam convergentes com os interesses do governo brasileiro durante o governo Lula.

\section{Andrade Gutierrez na República do Congo}

A Andrade Gutierrez (AGSA) foi fundada em I948 e sempre foi uma companhia privada. Os laços desse grupo empresarial com o governo brasileiro podem ser verificados nas diversas concessões de rodovias que a empresa possui de distribuição e geração de energia elétrica, nas obras de responsabilidade estatal em que esteve e está envolvida e nos negócios nos quais detém participação acionária, como a Oi/ Telemar.

Com relação ao braço de telecomunicações da AGSA, verifica-se forte interação com o governo nacional em nível acionário. Diversos fundos de empresas estatais (Funcef, Previ e Petros), além do BNDESPAR, têm participação acionária e controlam, conjuntamente à AGSA, a Oi/Telemar ${ }^{45}$.

A internacionalização da AGSA teve início em I984, quando realizou sua primeira obra internacional, na República do Congo. Em I987, a AGSA adquiriu a empresa de construção civil portuguesa Zagope, por meio da qual aumentou sua presença e sua experiência internacionais, visto que tal empresa lusitana já realizava obras na África. É por meio da Zagope que a AGSA atua no mercado africano, aproveitando-se do conhecimento da marca naqueles países. Desde 2008, a AGSA (também por meio da Zagope) voltou a atuar no Congo.

Como uma grande empresa privada nacional, a AGSA utiliza-se dos programas de financiamento do governo por meio do BNDES, de que são exemplos seus empréstimos no âmbito do Finame. Em 20Io, do total de aproximadamente R 2 bilhões em financiamentos contraídos no Brasil pelo segmento de concessões da AGSA, 94,8\% dos recursos foram obtidos junto a bancos estatais (BNDES, Caixa Econômica Federal e Banco do Brasil ${ }^{46}$. Ademais, diversos outros braços do conglomerado contraíram empréstimos com o BNDES durante o governo Lula.

É evidente a forte ligação entre a AGSA e o Estado brasileiro, destacando-se, durante o governo Lula, a flexibilização de lei previamente criada contra a concentração de serviços de telecomunicações sob o controle de poucas empresas,

44 MORAVCSIK, Andrew, op. cit.; RISSE-KAPPEN, Thomas, op. cit.

45 LAZZARINI, Sérgio G., op.cit.

46 AGSA. Relatório anual 20Io: Andrade Gutierrez. Disponível em: <www.agsa.com.br/arquivos/relatorio-anual/ RA_home.pdf> Acesso em: 29 maio 20I2. p. 82. 
quando da aquisição da Brasil Telecom pela Oi/Telemar (pois a transação era proibida pelo texto anterior da legislação47).

A quantidade de financiamentos obtidos junto a bancos governamentais e a participação de empresas estatais em empreendimentos em conjunto com a AGSA mostram que os interesses de ambos, em muitos casos, são convergentes/associados. Segundo Moravcsik ${ }^{48}$, isso poderia refletir uma assimetria na distribuição de poder no plano doméstico. Ou seja, a AGSA, como agente privado influente, lograria dividir seus custos com os demais atores.

No caso da promoção da PEB na África, no entanto, pode-se afirmar que a internacionalização de tal grupo empresarial brasileiro naquele continente não se iniciou por incentivo do governo Lula, visto que sua presença ali remonta à década de I980.

Empresas brasileiras, sobretudo a Andrade Gutierrez, atuaram no Congo por toda a década de I980, deixando-o por conta das guerras civis, nos anos I990. Com o fim dos conflitos, o Brasil voltou a importar petróleo congolês, de 2000 a 2005. Com a visita do ex-presidente Lula a Brazzaville, em 2007, foram firmados acordos para o estabelecimento mútuo de embaixadas. Desde a plena instalação da embaixada, em 2009, percebeu-se o aumento progressivo das exportações brasileiras, concentradas em carnes e seus derivados congelados. As empresas brasileiras presentes no Congo, como a AGSA, valem-se regularmente dos serviços consulares fornecidos pela embaixada e de apoio político quando necessário49.

O objetivo [da embaixada brasileira no Congo] é promover investimentos (retorno da Andrade Gutierrez e instalação da Asperbras) e exportações brasileiras (carnes e derivados congelados de boi, frango e suínos, açúcar, aço, ferro, cimento, serviços), negociando o perdão de parte substantiva da dívida congolesa num quadro favorável às empresas brasileiras. [...] [O Congo] tem apoiado praticamente todos os candidatos brasileiros nos mais diversos foros internacionais ${ }^{50}$.

Por ocasião de sua visita ao Congo, em 2007 - ano anterior à primeira obra da AGSA pós-década de I980 -, Lula anunciou que os estudos de perdoar a dívida de cerca de US\$ 400 milhões daquele país com o governo federal do Brasil já estavam quase concluídos. Seriam perdoados $90 \%$ do débito, e os Io\% restantes (cerca de US\$ 40 milhões) seriam saldados por meio de uma linha de financiamento para que empresas brasileiras fizessem obras de infraestrutura no país, de acordo com

47 LAZZARINI, Sérgio G., op. cit., p. II7.

48 MORAVCSIK, Andrew, op. cit.

49 HEIMBURGER, Felipe Dutra de Carvalho, op. cit.

50 Ibidem. 
a própria declaração à imprensa do então presidente Lula ${ }^{51}$. O referido perdão de dívida foi feito com vistas ao benefício de empresas brasileiras que já atuassem ou que viessem a atuar no país, depreendendo-se, portanto, que a visita de Lula ao Congo visou também a estimular a celebração de contratos entre empresas brasileiras já presentes no país, como a AGSA, e o governo congolês.

O governo brasileiro, portanto, fomenta a integração Brasil-Congo via intercâmbio comercial utilizando o perdão de dívida como moeda de troca, privilegiando companhias nacionais na execução das obras no país africano. Ressalta-se que a AGSA, especificamente, seria preferida pelo governo brasileiro (a player) a conquistar os contratos citados e outros novos no Congo:

O Brasil já perdoou débitos de outros países como Moçambique, também na África. A diferença no caso da República do Congo é que o Brasil pensa em aproveitar esse perdão para criar novas oportunidades de negócios [...]. O Brasil quer agora que o dinheiro que deveria ser usado para pagar a dívida seja canalizado para compra de bens e serviços brasileiros nesta etapa de investimentos congoleses.

[...] uma das perspectivas imediatas de contratação de obras pela República do Congo com o Brasil será a construção de uma ponte sobre o Rio Congo [...]. A construtora Andrade Gutierrez, que já construiu uma estrada na floresta tropical congolesa, várias vezes reverenciada pelo presidente congolês, Denis Sassou-Nguesso, durante a visita de Lula, é uma das fortes candidatas a fazer a ponte ${ }^{52}$.

A situação acima descrita demonstra grande convergência e associação de interesses de atores empresariais, destacadamente a AGSA, e do governo, passando pelas políticas públicas domésticas e externa, todas também convergentes neste estudo de caso, em que a internacionalização e a expansão de uma companhia nacional são colocadas como objetivo nas negociações financeiras com um país africano, conquistando espaço para a AGSA e apoio a pleitos políticos do Estado brasileiro no cenário mundial.

\section{Camargo Corrêa em Moçambique}

Empresa de capital privado, a Camargo Corrêa foi fundada em I939, atuando no ramo de construção civil. Desde a década de I950, a companhia tem participado de diversas grandes obras contratadas pelo governo brasileiro. A partir das reformas neoliberais

5 I SILVA, Luiz Inácio Lula da. Discurso do Presidente. Declaração à imprensa do Presidente da República, Luiz Inácio Lula da Silva, durante visita à República do Congo - Brazzaville, República do Congo, I6/Io/2007. Ministério das Relações Exteriores, Brasília, I6 out. 2007. Disponível em: <http://www.itamaraty.gov.br/ sala-de-imprensa/discursos-artigos-entrevistas-e-outras-comunicacoes/presidente-da-republica-federativado-brasil/279909774829-declaracao-a-imprensa-do-presidente-da-republica/ >. Acesso em: 29 maio 2012.

52 SANTOS, Chico. Brasil estuda perdoar dívida do Congo. Valor econômico, Rio de Janeiro, I7 de outubro de 2007. Disponível em: 〈http://oglobo.globo.com/economia/brasil-estuda-perdoar-divida-do-congo-4I473I3〉. Acesso em: I5 maio 2012. 
dos anos I990, a Camargo Corrêa adquiriu concessões de estradas federais e de usina hidrelétrica.

A expansão para o mercado africano consubstanciou-se em 20Io, quando a firma adquiriu controle acionário da empresa moçambicana Cimentos de Nacala e iniciou a construção da mina de carvão operada pela Vale em Moçambique, bem como a de uma usina hidrelétrica. Esses foram os maiores investimentos da Camargo Corrêa em solo africano, mas não os primeiros, pois a empresa já fizera negócios anteriormente no continente por intermédio de consórcios ou participação acionária em empresas que operavam na região.

Ainda que as decisões de investimento sejam tomadas por parte do conselho de administração da empresa analisada, são relevantes as interações com o governo brasileiro e, também, deve ser ressaltado o fato de, justamente durante o governo do PT, quando a África obteve tamanho destaque na promoção da política externa, ter a Camargo Corrêa invertido tantos recursos em países do continente - e, mais especificamente, em Moçambique.

Durante o governo Lula, Moçambique recebeu perdão de dívida do país com o Brasil, em 2004; teve instalada uma fábrica de antirretrovirais em seu território e pessoal treinado, empreendimento totalmente pago pelo Brasil53; ocorreram trocas de visitas oficiais entre o presidente brasileiro e seu homólogo moçambicano; e firmaram-se contratos de cooperação bilateral.

No âmbito doméstico brasileiro, a Camargo Corrêa obteve diversos grandes financiamentos por parte do BNDES 54 durante o governo Lula, demonstrando não somente sua capacidade financeira e sua potencialidade de crescimento (coadunando os estímulos às políticas públicas de desenvolvimento industrial implementadas durante o governo Lula), mas também estreita relação com o governo.

A entrada em Moçambique pode ter sido motivada, primeiramente, pelo contrato de construção da mina de carvão da empresa Vale naquele país. Entretanto, a decisão de seguir investindo no país, inclusive com operações no setor de cimento, mostra, além de ambiente empresarial favorável, que os esforços de boas relações do governo brasileiro com aquele país podem ter contribuído positivamente para a diminuição dos riscos de inversão da companhia no referido contexto. Trata-se de um grupo empresarial de destaque no plano doméstico e que demonstra relação sincrônica com os movimentos de integração Brasil-África promovidos pelo governo. Verificam-se, portanto, interesses convergentes entre a Camargo Corrêa e o Estado brasileiro e suas políticas públicas, no período estudado, tanto no plano doméstico quanto no internacional.

53 MINISTÉRIO DAS RELAÇÕES EXTERIORES. Visita do presidente Luiz Inácio Lula da Silva a Moçambique, nota n. 569. Maputo, I7 out. 2008. Disponível em: <http://www.itamaraty.gov.br/sala-de-imprensa/notas-aimprensa/2008/Io/I4/visita-do-presidente-luiz-inacio-lula-da-silva-a〉 Acesso em: I8 maio 2012.

54 Ver: PUERARI, Gustavo M., op. cit., p. I33. 


\section{CONSIDERAÇõES FINAIS}

Durante o governo de Luiz Inácio Lula da Silva, o Brasil logrou forte aumento de sua proeminência no contexto internacional. $\mathrm{O}$ empreendimento de uma política externa com ênfase em relações Sul-Sul em seus dois mandatos trouxe novo ânimo e reposicionou o país no cenário internacional, além de ter beneficiado atores do setor produtivo brasileiro.

Verificaram-se nos estudos de caso convergências de interesses e associações de estratégias entre membros do setor produtivo e o Estado brasileiro. Os atores privados domésticos estudados, interessados em aumentar suas operações internacionais e aproveitando-se de todos os benefícios providos pelo governo brasileiro e de suas ligações com o mesmo (financiamentos, participação acionária, políticas públicas, utilização de perdão da dívida como moeda de troca etc.), foram parte integrante da manifestação das preferências estatais no cenário internacional.

Ainda que não se possa generalizar o impacto das referidas convergências e associações a todo o empresariado doméstico, percebe-se que as estruturas domésticas brasileiras influenciaram e criaram canais de associação com membros do empresariado nacional, permitindo que grupos privados fizessem uso de estratégias políticas que também os beneficiassem. O inverso também se verificou, com o governo influenciando e fomentando atores privados a trabalharem convergentemente com seus interesses políticos da agenda Sul-Sul. Confirmaram-se, nos casos estudados, a convergência e a associação de interesses estatais e das empresas privadas e que o peso econômico desses grandes atores privados resultou em influência e ganhos político-financeiros.

As políticas públicas domésticas e externa foram conjugadas de maneira a incluir membros do setor produtivo como peça importante para o alcance de objetivos internacionais do governo. As convergências e associações mútuas verificadas entre o Estado brasileiro durante o governo Lula e parte do empresariado nacional proporcionaram ganhos para ambos, diminuição de riscos ao segundo e suporte ao processo político empreendido pelo Brasil no período.

\section{SOBRE O AUTOR}

GUSTAVO MIRANDA PUERARI é analista de Relações Internacionais do Instituto Brasileiro de Geografia e Estatística - IBGE. Mestre em Relações Internacionais pela Pontifícia Universidade Católica do Rio de Janeiro - PUC-Rio.

E-mail: gustavopuerari@gmail.com 


\section{REFERÊNCIAS BIBLIOGRÁFICAS}

ABDENUR, Adriana Erthal; SOUZA NETO, Daniel Marcondes de. Brazil and African security. CMI Reports, Bergen (Noruega), R, n. 4, 20I4.

AGSA. Relatório anual 20Io: Andrade Gutierrez. Disponível em: <www.agsa.com.br/arquivos/relatorio-anual/RA_home.pdf >. Acesso em: 29 maio 2012.

ARDISSONE, Carlos Maurício Pires e Albuquerque. Ideias, instituições e lideranças na política externa brasileira de propriedade intelectual: uma abordagem comparada dos governos Fernando Henrique Cardoso e Luiz Inácio Lula da Silva (I995-20I0). Tese (Doutorado). Instituto de Relações Internacionais - IRI, Pontifícia Universidade Católica do Rio de Janeiro - PUC-Rio, Rio de Janeiro, $20 I I$.

BOSCHI, Renato; DINIZ, Eli; SANTOS, Fabiano. Elites políticas e econômicas no Brasil contemporâneo: a desconstrução da ordem corporativa e o papel do Legislativo no cenário pós-reforma. São Paulo: Fundação Konrad Adenauer, 2000.

BNDES - Banco Nacional de Desenvolvimento Econômico e Social. BNDES aprova financiamento de R\$ 7,3 bilhões para Vale realizar investimentos no Brasil até 20I2. BNDES, Rio de Janeiro, I abr. 2008. Disponível em: <http://www.bndes.gov.br/SiteBNDES/bndes/bndes_pt/Institucional/Sala_de_Imprensa/Noticias/2008/2008040I_not054_08.html >. Acesso em: 20 maio 2012.

BRASIL. Decreto n. 5.770, de 8 de maio de 2006. Brasília, DF: Diário Oficial da União, 9 de maio de 2006. ISSN I677-7042.

. Decreto n. 6.422, de 2 de abril de 2008. Brasília: Diário Oficial da União, 3 de abril de 2008.

CAMPOS, Pedro Henrique Pedreira. Empresários, ditaduras e política externa brasileira. Continentes, Seropédica, ano 3, n. 4, 2014.

. Estranhas catedrais: as empreiteiras brasileiras e a ditadura civil-militar,I964-I988. Niterói: UFF, 20I4.

CERVO, Amado Luiz; BUENO, Clodoaldo. História da política exterior do Brasil. 3. ed. ampl. Brasília: UnB, 2008.

DINIZ, Eli; BOSCHI, Renato. Empresários, interesses e mercado: dilemas do desenvolvimento no Brasil. Belo Horizonte: UFMG; Rio de Janeiro: Iuperj, 2004.

EBOLI, Evandro. Lula anuncia perdão da dívida com o Congo, mas com uma condição. O Globo. Rio de Janeiro, I6 de outubro de 2007. Disponível em: <http://oglobo.globo.com/economia/lula-anuncia-perdao-da-divida-com-congo-mas-com-uma-condicao-4I48I98 >. Acesso em: I5 maio 2012.

FDC - Fundação Dom Cabral. Ranking das transnacionais brasileiras 20Io: repensando as estratégias globais. Fundação Dom Cabral, Belo Horizonte. Disponível em: <http://www.fdc.org.br/professoresepesquisa/publicacoes/Paginas/publicacao-detalhe.aspx?publicacao=I8I23>. Acesso em: Io maio $20 \mathrm{I2}$.

GUEDES, Ana Lúcia. Internacionalização de empresas como política de desenvolvimento: uma abordagem de diplomacia triangular. RAP, Rio de Janeiro, 40(3), mai.jun. 2006, p. 335-356.

GUEDES, Ana Lúcia. Negócios internacionais. São Paulo: Thomson Learning, 2007.

HEMAIS, Carlos Alberto (Org.). O desafio dos mercados externos: teoria e prática na internacionalização da firma. v. I. Rio de Janeiro: Mauad, 2004.

IPEA - Instituto de Pesquisa Econômica Aplicada. Cooperação brasileira para o desenvolvimento internacional: 2005-2009. Brasília: Ipea, Agência Brasileira de Cooperação - ABC, 20Io.

LAZZARINI, Sérgio G. Capitalismo de laços: os donos do Brasil e suas conexões. Rio de Janeiro: Elsevier, $20 I I$. LIMA, Maria Regina Soares; HIRST, Monica. Brasil como país intermediário e poder regional. In: LIMA, M.R.S.; HIRST, Monica (Org.). Brasil, Índia e África do Sul. Rio de Janeiro: Paz e Terra, 2009. MINISTÉRIO DO DESENVOLVIMENTO, INDÚSTRIA E COMÉRCIO EXTERIOR. Programa Integração 
com a África. [s.l.], jun. 20Io. Disponível em: <http://www.pdp.gov.br/Relatorios\%2ode\%20Programas/ AfricaI_com.pdf $>$. Acesso em: 5 jun. 2012.

MINISTÉRIO DAS RELAÇÕES EXTERIORES. Cúpula América do Sul-África - ASA . Abuja, 30 nov. 2006. Disponível em: <http://www.itamaraty.gov.br/temas/mecanismos-inter-regionais/cupula-americado-sul-20I3-africa-asa/>. Acesso em: 20 jul. 20II.

. Abertura da I Reunião de Altos Funcionários do Mecanismo América do Sul-África. Brasília, Io de junho de 2008. Disponível em: <http://www.itamaraty.gov.br/sala-de-imprensa/notas-a-imprensa/2008/o6/o9/abertura-da-i-reuniao-de-altos-funcionarios-do >. Acesso em: I8 maio 2012.

.Visita do presidente Luiz Inácio Lula da Silva a Moçambique, nota n. 569. Maputo, I7 de outubro de 2008. Disponível em: <http://www.itamaraty.gov.br/sala-de-imprensa/notas-a-imprensa/2008/Io/I4/ visita-do-presidente-luiz-inacio-lula-da-silva-a $>$. Acesso em: I8 maio. 2012.

. Cúpula América do Sul-Países Árabes - Aspa. Doha, 3I de março de 2009. Disponível em: <http:// www.itamaraty.gov.br/temas/mecanismos-inter-regionais/cupula-america-do-sul-paises-arabes-aspa>. Acesso em: I9 maio. 2012.

. Balanço de política externa: 2003-20Io. [Brasília]: Secretaria de Planejamento Diplomático/MRE, [20II].

MORAVCSIK, Andrew. Taking preferences seriously: a liberal theory of international politics. International Organization, 5I, 4, Outono, I997.

OLIVEIRA, Amâncio Jorge de; PFEIFER, Alberto. O empresariado e a política exterior do Brasil. In: LESSA, A. C.; OLIVEIRA, H. A. de (Org.). Relações internacionais do Brasil: temas e agendas. v. 2. São Paulo: Saraiva, 2006.

PASSOS, Ieda; GALVÃO, Fábio (Org.). Relatório de prestação de contas do Ministério do Desenvolvimento, Indústria e Comércio Exterior 2003-2006: Indústria e comércio exterior: caminhos para o desenvolvimento. [Brasília]: [s.n.] [2007?].

PERES, Wilson; PRIMI, Annalisa. Theory and practice of industrial policy: evidence from the Latin American experience. Cepal, Serie Desarrollo Productivo, Santiago do Chile, I87, n. I, 2008, p. I-5I, FEB.

PINHEIRO, Leticia; MILANI, Carlos R. S. (Org.). Política externa brasileira: as práticas da política e a política das práticas. Rio de Janeiro: FGV, 2012.

PUERARI, Gustavo M. Empresariado e política externa brasileira para a África: convergências e associações no governo Lula. Dissertação (Mestrado). Instituto de Relações Internacionais - IRI da Pontifícia Universidade Católica do Rio de Janeiro - PUC-Rio, Rio de Janeiro, 2012.

RIBEIRO, Cláudio Oliveira. A política africana do governo Lula (2003-2006). Tempo Social, São Paulo, v. 2I, n. 2, 2009, p. I85-209. Disponível em: <http://www.jtrindade.com.br/wp-content/uploads/20II/II/ Brasil_Africa_Gov_Lula_20Io.pdf $\rangle$. Acesso em: II jun. 2012.

RISSE-KAPPEN, Thomas. Bringing transnational relations back in: non-state actors, domestic structures, international institutions. Cambridge: Cambridge University, I995.

ROMERO, Cristiano. Sucessão na Vale terá solução interna. Valor econômico, Rio de Janeiro, 24 de março de 20II. Disponível em: <http://www.valor.com.br/arquivo/878877/sucessao-na-vale-tera-solucao-interna\#ixzzIvpNi6hL5>. Acesso em: 24 maio 2012.

SANTOS, Chico. Brasil estuda perdoar dívida do Congo. Valor econômico, Rio de Janeiro, I7 de outubro de 2007. Disponível em: <http://oglobo.globo.com/economia/brasil-estuda-perdoar-divida-do-congo-4I473I3>. Acesso em: I5 maio 2012.

SILVA, Luiz Inácio Lula da. Discurso do Presidente. Declaração à imprensa do Presidente da República, Luiz Inácio Lula da Silva, durante visita à República do Congo - Brazzaville, República do Congo, I6/Io/2007. Ministério das Relações Exteriores, Brasília, I6 out. 2007. Disponível em: <http://www. 
itamaraty.gov.br/sala-de-imprensa/discursos-artigos-entrevistas-e-outras-comunicacoes/presidenteda-republica-federativa-do-brasil/279909774829-declaracao-a-imprensa-do-presidente-da-republica>. Acesso em: 29 maio 2012.

VALE. Golden shares. Disponível em: <http://www.vale.com/brasil/pt/investors/company/corporategovernance/golden-share/Paginas/default.aspx>. Acesso em: 24 maio 2012. 